Patients' perception on interpersonal skills of doctor-patient relationship in Fatmawati Public Teaching Hospital, Syarif Hidayatullah Hospital, and Harapan Bunda Hospital Jakarta Indonesia

Ekayanti, Fika $₫$

State Islamic University of Syarif Hidayatullah Jakarta, Indonesia (fikaekayanti@uinjkt.ac.id;

fikaekayanti@yahoo.com)

Dwiyanti, Sophie

State Islamic University of Syarif Hidayatullah Jakarta, Indonesia (opinsani@yahoo.com)

Nasrudin, Nasrudin

State Islamic University of Syarif Hidayatullah Jakarta, Indonesia (nidursan17@ gmail.com)

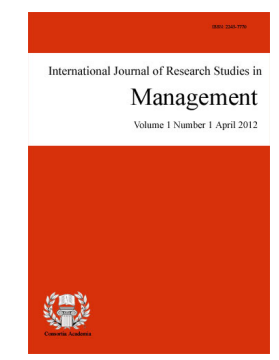

ISSN: $2243-7770$ Online ISSN: 2243-7789

OPEN ACCESS

\title{
Abstract
}

Professionalism in doctor-patient relationship is influenced by the capability on performing excellent interpersonal skills. Those are consisted of verbal and non-verbal communication skills, listening skills, negotiating skills, problem solving skills, decision making skills, and assertive skills. Kalamazoo Consensus Statement set those skills into seven aspects of communication and interpersonal skills process. The hypothesis of the study was that no significant difference based on patient's perception to doctors' interpersonal skills between different places of work. To identify the difference of doctor's characteristic of interpersonal skills in RSUP Fatmawati as the public hospital, RS Syarif Hidayatullah as Islamic private hospital and RS Harapan Bunda as the general private hospital. The study design was cross sectional with 150 samples for each hospital (total samples were 450 samples). Data was gathered by using the questionnaires within September to December 2013, and analyzed by SPSS 16 using Pearson chi square test. There was significant difference between doctors characteristic of interpersonal skills in RSUP Fatmawati, RS Syarif Hidayatullah dan RS Harapan Bunda. The lowest interpersonal skill was obtained by RS Syarif Hidayatullah. The decent attitude and behavior of doctor's performance from patients' perspective was low (20.7\%). The doctor's characteristic of interpersonal skills has significantly different based on the work place. It needs hospital intervention to improve the quality of service for the patients.

Keywords: professionalism; doctor and patient relationship; interpersonal skills; public hospital; private hospital 


\section{Patients' perception on interpersonal skills of doctor-patient relationship in Fatmawati Public Teaching Hospital, Syarif Hidayatullah Hospital, and Harapan Bunda Hospital Jakarta Indonesia}

\section{Introduction}

Medical doctor is a profession that requires complex competencies, including knowledge of health sciences, clinical skills, and skills to interact with patients. To perform the profession, someone have to commit to the professional standard that has been develop by the medical council, have to acquire the recognition certificate or professional license, as well as to conform to code of medical conduct and values of professionalism while carrying out the professional duties. The values of medical professionalism are always being a concern in the society. According to Stern (2006), the principles of professionalism are excellence, humanism, accountability, and altruism. Humanism and altruism are closely related to the values that have to be considered by the doctor while presenting the professional services. Altruism is a desire to provide the best treatment for the patients, whereas humanism is comprised with responsiveness, empathy and autonomy. Project of the ABIM Foundation AAF, and European Federation of Internal Medicine (2002) has also defined that the principles of professionalism are consisted of competence, honest to the patient, patient's confidentiality, good relationship with patients, high quality of health care and accessibility to health services.

Wagner, Hendrich, Moseley, and Hudson et al. (2007) has done a qualitative research that defined the concept of professionalism based on the perception of 4 group stakeholders. They were faculties, doctors, medical students and patients. Based on the focus group analysis between those groups, there was a different emphasis on valuing professionalism. In patients and students' perception, the emphasis of the value was more on the interpersonal relationships, while in perception of the faculties and doctors, the emphasis was more on the knowledge and skills of the doctor.

In the relationship between doctor and patient, the altruism and humanism were the main aspects that should be considered when effective communication was made in the interaction of the doctors and their patients. However, the evidence that occurred within the last few years showed that the most complaint in the society was that the doctors have showed less competence to the communication and less empathy in the interaction (Dharmawan, 2010). Indonesian issue on the low quality of health services and the malpractice or ethical violation, were most caused by professionalism problems of bad performance in presenting the communication to the patients. It certainly can influence the perception and image of the doctor's performance in the society.

Some forms of bad communication were often showed in the consultation process. For example was when the doctor immediately cut off the patient story which was just started to explain about his health problem. Doctor also often did not ask the patient feeling about his condition, provided only short information of patient's health condition and commonly used medical terminology that cannot be understood by the patient (Kurtz, Silverman, \& Draper, 2005). The communication between doctor and patient would occur effectively when the doctor has good interpersonal skills (Duffy, Gordon, Whelan, Cole-Kelly, \& Frankel et al., 2004). The values that attach to someone interpersonal skills are influenced by the values held in the community. It can be observed along the process of doctor and patient interaction.

In many countries, there has been an increasing trend of research theme on doctor's interpersonal skills; however, there was still lack of evidence about this topic in Indonesia. Many researches in Indonesia were generally oriented only on communication skills. Therefore, we were interested in collecting more data on the doctor's interpersonal skills performance according to the patient's perception when they interacted with the doctor in three different institutions. Those were the public hospital; Fatmawati Public Teaching Hospital and the other were private hospitals; Syarif Hidayatullah hospital and Harapan Bunda hospital. 


\subsection{Interpersonal skills}

Interpersonal skills are human behaviors used to achieve their targets in the interaction processes (Hayes, 2002). The skills include micro skills such as listening skills, information-getting and information-sharing skills, negotiating skills, and others like empathy, gestures, etc. These skills are important in many types of work, including in doctor-patient relationship in order to achieve effective communication. The concept of "patient centeredness" has changed doctors' domination. Interpersonal skills of the doctors play a big role to patient satisfaction and the quality of health services. Interpersonal skills would be different in West and East culture. A study by Birket (2013) showed that Chinese young adults had greater self-compassion than Americans, on the contrary, empathy in American young adult were higher than Chinese. Americans had lesser feelings of anxiety and unease in interpersonal interaction. In Indonesia, Claramita (2012) found that Southeast Asia culture has great influenced on doctor-patient communication behavior skills. However, patients' perception about the interpersonal skills within different institutions has not been observed.

\subsection{Place of work}

Different workplace would have different culture and behavior of working environment (Gibson, Ivancevich, Donnelly, \& Konopaske, 2006). In Indonesia, there are two types of hospital management; public and private hospital. Public hospital runs by government, while private hospital runs by individual or corporate management. Interaction between doctor and patient should not be different between those hospitals; because there are standard competences that doctor has to be accomplished when he practices as physician. In Pakistan, patients have better satisfaction for the services in private hospital rather than in public hospital (Khattak, Alvi, Yousaf, Abideen Shah, Turial, \& Akhter, 2012). In Indonesia, there is lack of research that compares the patient satisfaction in public and private hospital.

\section{Method}

\subsection{Research Design}

This study was designed in a cross sectional method that compared the mode of three groups on the interpersonal skills based on patient's perception. The independent variables were the doctor's place of work, while the dependent variable was doctor's interpersonal skills. The inclusion criteria for this study was that respondents were outpatient with age equal and above 15 years old, while the exclusion criteria was only when the respondent was not fulfill all the items in the questionnaire. While for the doctors that were being evaluated, we included all doctors whose patients were agreed to be our respondents. Based on doctor competence, we agreed that both general practitioners and specialists should have the same level of competency in demonstrating their interpersonal skills to interact with their patients (Duffy et al., 2004).

\subsection{Participants and Procedures}

The samples were taken by consecutive sampling. The minimum samples required were 140 respondents by $95 \%$ level of confidence. With dropout sample anticipation, the sample size was added to be 150 respondents for each hospital. Total samples used were 450 respondents; those were 150 respondents taken from Syarif Hidayatullah hospital, 150 respondents from Harapan Bunda hospital and 150 other respondents from Fatmawati hospital. The sample distribution of each hospital was described in table 1. In general, the gender distribution in each hospital was almost similar. The two private hospitals had more than $60 \%$ female patients and age range between 15-55 years whereas Fatmawati hospital had 57\% female patients with older range of age, between 56-90 years. 
Ekayanti, F., Dwiyanti, S., \& Nasrudin, N.

\section{Table 1}

Distribution of Research Samples

\begin{tabular}{llccc}
\hline \multirow{2}{*}{ No Category } & \multicolumn{3}{c}{ Hospital } \\
\cline { 2 - 4 } & \multicolumn{1}{c}{ UIN Syahid } & Harapan Bunda & Fatmawati \\
\hline \multirow{2}{*}{2} & Sex/Gender & & & $64(43 \%)$ \\
& Male & $53(35 \%)$ & $48(32 \%)$ & $86(57 \%)$ \\
& Female & $97(65 \%)$ & $102(68 \%)$ & $66(44 \%)$ \\
& Age Category & & & $84(56 \%)$ \\
& $15-55$ year & $131(87 \%)$ & $146(97 \%)$ & $113(75.4 \%)$ \\
& $56-90$ year & $19(13 \%)$ & $4(3 \%)$ & $37(24.6 \%)$ \\
& School & & & $1(0.7 \%)$ \\
& Junior-senior High School & $81(54 \%)$ & $79(52.6 \%)$ & $56(37.3 \%)$ \\
& Graduation & $69(47 \%)$ & $71(47 \%)$ & $35(23.4 \%)$ \\
& Occupation & & & $36(24 \%)$ \\
& Student & $58(38.7 \%)$ & $13(8.7 \%)$ & $22(14.7 \%)$ \\
& Wife House & $36(24 \%)$ & $19(12.7 \%)$ & $7(4.7 \%)$ \\
& Entrepreneur & $18(12 \%)$ & $14(9.3 \%)$ & $30(20 \%)$ \\
& Public Worker & $11(7.3 \%)$ & $65(43.3 \%)$ & $113(75.3 \%)$ \\
\hline
\end{tabular}

Whereas the description of the doctors that were observed in those three hospitals were shown in the table 2 . The inclusion criteria for this study was that respondents were outpatient with age equal and above 15 years old, the exclusion criteria was only when the respondent was not fulfill all the items in the questionnaire. While for the doctors that were being evaluated, we included all doctors whose patients were agreed to be our respondents. Based on doctor competence, both general practitioners and specialists should have the same level of competency in demonstrating their interpersonal skills to interact with their patients (Duffy et al., 2004).

Table 2

Doctors' description

\begin{tabular}{|c|c|c|c|c|}
\hline \multirow{2}{*}{ No } & \multirow{2}{*}{ Category } & \multicolumn{3}{|c|}{ Hospital } \\
\hline & & UIN Syahid & Harapan Bunda & Fatmawati \\
\hline \multirow[t]{3}{*}{1} & Doctor & & & \\
\hline & General Practitioners & $90(60 \%)$ & $61(40.7 \%)$ & - \\
\hline & Specialist & $60(40 \%)$ & $89(59.3 \%)$ & $150(100 \%)$ \\
\hline \multirow[t]{5}{*}{2} & Doctor Age & & & \\
\hline & $25-30$ & $7(4.7 \%)$ & $2(1.3 \%)$ & $2(1.5 \%)$ \\
\hline & $31-40$ & $57(38 \%)$ & $60(40 \%)$ & $56(42.1 \%)$ \\
\hline & $41-50$ & $71(47 \%)$ & $79(52.7 \%)$ & $38(28.6 \%)$ \\
\hline & $>50$ & $15(10 \%)$ & $9(6 \%)$ & $37(27.8 \%)$ \\
\hline
\end{tabular}

The data was collected by using a questionnaire that was made based on seven aspects in Kalamazoo Consensus for the communication and interpersonal skills assessment process (Duffy et al., 2004). The questionnaire had been previously validated by analysis of Cronbach's Alpha 0.942 for the second part and 0.795 for third part. The mode value was used to represent the most often scores were chosen by the respondents in each aspect of communication. The mode value was stated as respondents' perception to the doctor performance. The study has been approved with consent from the hospitals and by the Ethical Committee of Fatmawati hospital. The questionnaires were distributed to the respondents within September to December 2013. 


\subsection{Measures}

The interpersonal skills questionnaire was consisted of three parts. The first part was the characteristics of respondents and doctors who were being evaluated, the second was the Likert statement that was developed from seven aspects of communication and interpersonal skills in Kalamazoo Consensus, and the third part was the patient's opinion on the doctor's attitude and behavior within the process of interaction with the patient.

In the second part, 58 items were included in the seven aspects of communication and interpersonal skills process. Each item comprised a statement that represented a form of interpersonal skills related to the aspect of communication process. The first aspect were consisted of 10 items of statement, the second aspect were consisted of 11 items of statement, the third aspect were consisted of 7 items, the fourth aspect was consisted of 9 items, the fifth aspect was consisted of 9 items, the sixth aspect was consisted of 8 items, and the last aspect was consisted of 4 items of statement. The statement of this part was using a Likert Scale in 4 categories, those were very inappropriate, inappropriate, appropriate, and very appropriate.

The third part was consisted of 22 item statements. The statement was about the patient's evaluation on the attitudes and behaviors that was observed in the doctor-patient interaction. The instrument was responded in a checklist of yes or no.

\subsection{Statistical Analysis}

The data result from the questionnaires was analyzed by using SPSS 16 with Pearson chi-square test. Level of significance used for all analysis was $\alpha=0.05$.

\section{Results}

From the questionnaires' analysis, a table was made to describe the results of the second part of the questionnaire. There were three independent variables (the hospital as the doctors' work place) and 4 Likert scale criteria that were the dependent variable (very appropriate, appropriate, inappropriate and very inappropriate). However, from the seven aspects evaluated, only the second and seventh aspects can use the Pearson chi-square test with a $3 \times 4$ table. The other five aspects were modified into a $3 \times 2$ table. For the $3 \times 2$ table, the Likert scale of very appropriate and appropriate were classified as the same category, that was appropriate, while inappropriate and very inappropriate were categorized into inappropriate.

The results for the patients' perception on the aspects interpersonal skills in doctor-patient relationship were shown in table 3. This result showed that there was a significant difference of doctor's performance in the different hospitals.

The first aspect of building rapport with patients from all of the hospitals according to the patient's perception was 93.6\% (table 3x2). Among all hospitals, Syarif Hidayatullah hospital has the lowest results with $84 \%$ patients answered appropriate attitude of doctors in building rapport with patients. While Harapan Bunda hospital has the highest appropriate answered of the aspect $(99.3 \%)$, and Fatmawati hospital followed with 97.3\% of appropiate answered. Patients who answered that the doctor had inappropriate interpersonal skill in building rapport with patients were only $6.4 \%$, those were consecutively Harapan Bunda hospital $(0.7 \%)$, Fatmawati hospital $(2.7 \%)$ and the most inappropriate answered was from Syarif Hidayatullah hospital's patients with results of $16 \%$. 
Ekayanti, F., Dwiyanti, S., \& Nasrudin, N.

Table 3

Results

\begin{tabular}{|c|c|c|c|c|}
\hline \multirow{2}{*}{ Category } & \multicolumn{3}{|c|}{ Hospital } & \multirow{2}{*}{$\begin{array}{l}\overbrace{0}^{\circ} \\
\stackrel{1}{0} \\
0\end{array}$} \\
\hline & UIN Syahid & Harapan Bunda & Fatmawati & \\
\hline \multicolumn{4}{|l|}{ 1. Building rapport with patients } & \multirow{3}{*}{$\begin{array}{l}\hat{\circ} \\
\dot{\delta}\end{array}$} \\
\hline Appropriate & $126(84 \%)$ & $149(99.3 \%)$ & $146(97.3 \%)$ & \\
\hline Inappropriate & $24(16 \%)$ & $1(0.7 \%)$ & $4(2.7 \%)$ & \\
\hline \multicolumn{5}{|c|}{ 2. Opening interview and having discussion with patients } \\
\hline Very appropriate & $7(4.7 \%)$ & $20(13.3 \%)$ & $7(4.7 \%)$ & \multirow{4}{*}{$\stackrel{\circ}{8}$} \\
\hline Appropriate & $78(52 \%)$ & $81(54 \%)$ & $100(66.7 \%)$ & \\
\hline Inappropriate & $54(36 \%)$ & $44(29.3 \%)$ & $42(28 \%)$ & \\
\hline Very inappropriate & $11(7.3 \%)$ & $5(3.3 \%)$ & $1(7 \%)$ & \\
\hline \multicolumn{4}{|c|}{ 3. Obtaining information from patients } & \multirow{3}{*}{$\begin{array}{l}\hat{ᄋ} \\
\stackrel{8}{8}\end{array}$} \\
\hline Appropriate & $105(70 \%)$ & $138(92 \%)$ & $133(88.7 \%)$ & \\
\hline Inappropriate & $45(30 \%)$ & $12(8 \%)$ & $17(11.3 \%)$ & \\
\hline \multicolumn{4}{|c|}{ 4. Understanding patients' perspective } & \multirow{3}{*}{$\begin{array}{l}\hat{O} \\
\stackrel{8}{\circ}\end{array}$} \\
\hline Appropriate & $86(57.3 \%)$ & $105(70 \%)$ & $140(93.3 \%)$ & \\
\hline Inappropriate & $64(42.7 \%)$ & $45(30 \%)$ & $10(6.7 \%)$ & \\
\hline \multicolumn{4}{|l|}{ 5. Sharing information to patients } & \multirow{3}{*}{$\begin{array}{l}\hat{ᄋ} \\
\stackrel{8}{8}\end{array}$} \\
\hline Appropriate & $114(76 \%)$ & $142(94.7 \%)$ & $139(92.7 \%)$ & \\
\hline Inappropriate & $36(24 \%)$ & $8(5.3 \%)$ & $11(7.3 \%)$ & \\
\hline \multicolumn{4}{|c|}{ 6. Achieving agreement with patient } & \multirow{3}{*}{$\begin{array}{l}\hat{\rho} \\
\stackrel{8}{8}\end{array}$} \\
\hline Appropriate & $89(59.3 \%)$ & $120(80 \%)$ & $108(72 \%)$ & \\
\hline Inappropriate & $61(40.7 \%)$ & $30(20 \%)$ & $42(28 \%)$ & \\
\hline \multicolumn{5}{|c|}{ 7. Giving additional information and closing discussion with patients } \\
\hline Very appropriate & $8(5.3 \%)$ & $20(13.3 \%)$ & $18(12 \%)$ & \multirow{4}{*}{$\begin{array}{l}\hat{0} \\
\stackrel{8}{0}\end{array}$} \\
\hline Appropriate & $77(51.3 \%)$ & $105(70 \%)$ & $84(56 \%)$ & \\
\hline Inappropriate & $56(37.3 \%)$ & $19(12.7 \%)$ & $48(32 \%)$ & \\
\hline Very inappropriate & $9(6 \%)$ & $6(4 \%)$ & - & \\
\hline
\end{tabular}

The second aspect of patients' evaluation (table 3) was the doctors' interpersonal skill in opening interview and having discussion with patients. In total respondents, it showed $57.6 \%$ appropriate and $7.6 \%$ very appropriate. Among all hospitals, Syarif Hidayatullah hospital had 52\% appropriate and 4.7\% very appropriate interpersonal skill in opening the interview and having a discussion with patient. Harapan Bunda Hospital had 54\% appropriate and $13.3 \%$ very appropriate, and the highest appropriateness in Fatmawati with $66.7 \%$ appropriate and $4.7 \%$ was very appropriate. Patients answered $31.1 \%$ inappropriate and $3.8 \%$ very inappropriate interpersonal skill in opening the interview and having a discussion with patient. The most inappropriate answer was to doctors in Syarif Hidayatullah hospital with 36\% inappropriate and $7.3 \%$ very inappropriate, whereas Fatmawati hospital had $28 \%$ inappropriate and $7 \%$ very inappropriate and Harapan Bunda hospital had $29.3 \%$ inappropriate and $3.3 \%$ very inappropriate.

The third aspect was about doctor's interpersonal skill in obtaining information from patients. It had 83.6\% appropriate answered from the patients. Among all hospitals, Syarif Hidayatullah hospital had 70\% appropriate, Fatmawati hospital had $88.7 \%$ appropriate and the highest was in Harapan Bunda hospital with $92 \%$ of appropriate answered. It showed that doctor's skill in obtaining information from patient was quite high. The inapproriate answered was $16.4 \%$ in total. The highest inappropriate answered was $30 \%$ in Syarif Hidayatullah hospital. It followed by $11.3 \%$ in Fatmawati hospital and $8 \%$ in Harapan Bunda hospital.

The fourth aspect that was doctors' interpersonal skill in understanding patients' perspective showed 73.6\% appropriate answered. Among all hospitals, Syarif Hidayatullah hospital had $57.3 \%$ answered that doctors had appropriate interpersonal skill. It followed by Harapan Bunda hospital with $70 \%$ and Fatmawati hospital with 93.3\%. While the inappropriate answered was $26.4 \%$ in total with Syarif Hidayatullah hospital had $42.7 \%$, Harapan Bunda hospital had 30\% and Fatmawati hospital had $6.7 \%$ inappropriate answered. 
Patients' perception on interpersonal skills of doctor-patient relationship in three Indonesian hospitals

The fifth aspect of doctors' interpersonal skill was sharing information to patients. It showed that $87.8 \%$ was approriate and $12.2 \%$ was inappropriate. Among all hospitals, Syarif Hidayatullah hospital had $76 \%$ patients who answered that doctors had appropriate interpersonal skill in sharing information with them, then followed by Fatmawati hospital with $92.7 \%$ appropriate answered and the highest was in Harapan Bunda hospital with $94.7 \%$ answered. Patients answered that the doctor had inappropriate interpersonal skill in sharing information to patients was $12.2 \%$. The highest inappropriate interpersonal skill was in Syarif Hidayatullah hospital with 24\%, then followed by Fatmawati and Harapan Bunda hospital with 7.3\%.

The sixth aspect of doctors' interpersonal skill had 70.4\% in total answered from the patients. It was about reaching an agreement with patients. The Syarif Hidayatullah hospital had 59.3\% patients who answered doctors' interpersonal skill of reaching an agreement with them was appropriate. It followed by Fatmawati hospital with $72 \%$ appropriate answered and the highest was in Harapan Bunda hospital with $80 \%$ appropriate answered. Whilst, inappropriate answered on doctors' interpersonal skill to achieve an agreement with patients was quite high with 29.6\%. The highest inappropriate answered was in Syarif Hidayatullah hospital with 40.7\%, then followed by Fatmawati hospital with $28 \%$ and Harapan Bunda hospital with $20 \%$ answered.

The last aspect shown in table 3 was about giving additional information and closing the discussion with patients. It had $59.1 \%$ appropriate and $10.2 \%$ very appropriate. Syarif Hidayatullah hospital had $51.3 \%$ patients' answered that doctors was appropiate and 5.3\% was very appropriate interpersonal skill in giving additional information and to closing the discussion with the patients. It followed by Fatmawati hospital that was about $56 \%$ appropriate and $12 \%$ very appropriate answered. The highest appropriate answered was in Harapan Bunda hospital with $70 \%$ appropriate and $13.3 \%$ very appropriate answered.

Patients answered quite high, that was $27.3 \%$ inappropriate and $3.3 \%$ very inappropriate interpersonal skills in providing the additional information and closing the discussion with the patients. The highest inappropriate answered was from patients in Syarif Hidayatullah hospital, that was $37.3 \%$ and very inappropriate was $6 \%$. Whereas, Fatmawati hospital had 32\% inappropriate answered and the lowest inappropriate answered was from patients in Harapan Bunda hospital with $12.7 \%$ and $4 \%$ very inappropriate answered. Every aspect has been analyzed by Pearson chi square test, with $\alpha$ lfa value was 0.05 . The P-value for the first, the third and the seventh aspects were 0.001 and the p-value for the second aspect was 0.001 . This showed that every aspect of interpersonal skills during the doctors' communication and interaction process had significantly differences among the independent variables, the doctors' place of works, which were Syarif Hidayatullah hospital, Harapan Bunda hospital and Fatmawati hospital.

The attitudes and behavior of doctors in doctor-patient relationship according to patients' perception was still low. Patients' opinion expressed that doctors only showed $20.7 \%$ that has good interpersonal skills behavior. Another $79.3 \%$ patients did not satisfy with doctors' attitude and behavior. Patients scored that doctor interpersonal skills attitude and behavior in Syarif Hidayatullah Hospital and Harapan Bunda Hospital was 28.7, whereas Fatmawati was very low at $4.7 \%$. From Pearson's chi square test with alfa value was 0.05 , there were significant differences in doctor attitudes and interpersonal in Syarif Hidayatullah Hospital, Harapan Bunda Hospital and Fatmawati Hospital with $p$-value 0.001.

\section{Discussion}

Based on the research result on every aspect of communication between doctor and patient, the doctors showed good interpersonal skills in the interaction between doctor and patient during patient's examination. However, when it was compared to each hospital, there was a significant difference between the interpersonal skills of doctors from the patients' point of view within their encounter to have the doctors' services in the different places (Syarif Hidayatullah hospital, Harapan Bunda hospital, and Fatmawati hospital).

According to Mansoer study (as cited in Suryawati, Dharminto, \& Shaluhiyah, 2006), patient satisfaction in the hospital has a significant relationship with doctor services of the inward patient, which specifically in the 
regularity of doctor visit in ward, how patient be examined, level of responsiveness (doctors' caring and reaction) to the patient's questions, informality and seniority of the doctor (Suryawati et al., 2006). This research was more focused on how the examination was done, level of responsiveness and informality of the doctors to their patients. It was no further research on the doctors' interpersonal skills.

Based on hypothesis of the study, there should be no difference from doctor's interpersonal skills in doctor-patient relationship within each hospital. It was constructed because of the fact that every graduate doctor has the same standard of competence that should be achieved, especially related to the professionalism and effective communication (Indonesian Medical Council, 2012). Besides that, the medical education curriculum has also have a similar goal to have nationally and there is also Indonesian Medical Association which controls the medical doctors with rules and ethics to put patients above the interest of individuals, groups or organizations, and respect the human rights and principles of biomedical ethics (Sadikin, 2008). However, the result showed that doctors who work in different hospital would perform different attitude and interpersonal behavior. Hospitals as the place of work may have its role on forming doctor's performance. Research on quality assurance in the public hospital of Indonesia showed that intervention of the hospital in order to have better service performance to the patients was influenced by the doctors' services (Pramono, 2005).

Previous study which was done by Herqutanto, Basuki, Jauzi, and Mansyur (2011) about the doctors' knowledge and skills on doctor-patient communication in Indonesia's primary health care services, showed that the doctors' knowledge and skills on doctor-patient communication were low and below the median value of skills' scores. However, there were no significant factors that influenced the level of knowledge and skills of the doctors. Another study that was done by Law and Britten (as cited in Herqutanto et al., 2011), the knowledge and skills of the doctors were influenced by the level of education and gender of the doctors, that was not shown in Herqutanto et al.'s study results. This study illustrates the competency of doctors in primary health care services that evaluated from the doctors themselves. It used different instrument, which was from Calgary-Cambridge Observation Guide (CCOG) as the questionnaire, which has been translated to Indonesian language. Compared to our study, the differences were in the focus theme, the research location, the target respondents and the questionnaire instrument.

The study that was done by Lee, Seow, Luo, and Koh (2008) in Singapore, showed that there was lower perception from medical students in Singapore to doctor-patient relationship that has partnership or equality characteristic compared to students' perception in the USA. It said that it might be occurred based on the difference in cultural value and expectation in doctor-patient relationship within different society (Lee et al, 2008). The study from Claramitha (2012) was also emphasized on the cultural competence as the important aspect that should be carefully considered by the medical doctors. These studies might also be an important factor that should be evaluated further on doctors' performance in their routine activities at the hospital.

From the studies that have been reported in Indonesia, there were no research specifically compared the different work of place related to the doctors' performance in doctor-patient relationship. This study would give a better description about the doctors' performance according to patients' point of view.

This study showed that in the first aspect of building rapport with patients' respondents that about $93.6 \%$ patients answered that the doctors had appropriate performance. Yet, it showed that Syarif Hidayatullah hospital had lowest perception on the doctors' interpersonal skills. Whilst, the highest perception according to patients was in Harapan Bunda hospital. Both of these hospitals were private hospitals with different background. Syarif Hidayatullah hospital is a private hospital with Islamic basis, whereas Harapan Bunda hospital is a private hospital with general background.

In the communication process, according to Nelson and Vega (2008), building a good relationship with the patient could be done by providing a warm greeting, eye contact, non-medical interaction, and asking how the patient's feeling at that time. Iragiliati (2006) in her research stated that it was important to strategically being polite and pay attention to the patient's cultural values. The patients also wanted their doctors to introduce 
Patients' perception on interpersonal skills of doctor-patient relationship in three Indonesian hospitals themselves, shake the patients' hand, and call their patients with their first name (Makaul, Zick, \& Green, 2007). Based on patient's opinion, this skill has already sufficiently demonstrated by the doctors.

The second aspect was the interpersonal skill of doctors in the opening interview and having discussion with patient. The results showed that doctors at the Syarif Hidayatullah hospital was the lowest, while the highest was from Fatmawati hospital. Fatmawati hospital is the public hospital that managed by the government, however this aspect showed that according to patients, the doctors' skill in opening interview and having discussion with the patient is better than the private hospital. It is also the teaching hospital as the place of clinical students learned that might influence the doctors' performance in Fatmawati hospital, though it needs further study to find the related factors to this situation.

From the third aspect, this was the interpersonal skill in obtaining information from the patient. Syarif Hidayatullah hospital was the lowest in performance, and the highest was Harapan Bunda hospital.

The fourth aspect which was understood the patient's perspective, had the highest doctors' performance in Fatmawati Hospital and the lowest in Syarif Hidayatullah hospital. The discrepancy between Fatmawati hospital to other hospitals was wide. There should be further study on the factor that could influence this situation, such as almost all respondents in the Fatmawati hospitals were usually not the first encounter to see the doctors because they had chronic diseases. On the other hand, the doctors might also have experienced with many patients that generally had similar problems, thus they could understand better the patients' perspective.

The highest answered from patients to the fifth aspect, which was sharing information with the patient, was in Harapan Bunda hospital and followed next by the Fatmawati hospital, whereas the lowest was in the Syarif Hidayatullah hospital. According to research conducted by Pramono (2006) for his thesis, the willingness of patients to return to the same hospital, in this case was Kartini public hospital of Jepara in 2004, was because the doctor showed responsiveness in their services. In this situation, responsiveness can be shown during the discussion with the patient of the second aspect and sharing the information with patients with sensitivity to the social signs, emotional, empathy and other non-verbal communication (Iragiliati, 2006).

The sixth aspect was achieving agreement with the patient. The highest appropriate answered was from Harapan Bunda hospital's doctors, while doctors at the Syarif Hidayatullah hospital had the lowest appropriate doctors' interpersonal skill of achieving agreement with the patients.

The seventh aspect was the skill in giving the additional information and closing the discussion. It showed that the highest appropriate answered based on patients' perspective was the doctors at Harapan Bunda hospital, and the lowest was from Syarif Hidayatullah hospital, while Fatmawati hospital has also had big discrepancy to the Harapan Bunda hospital.

From all aspects in Kalamazoo Consensus that have been evaluated by the questionnaire, it showed that in general, the doctors in Harapan Bunda hospital have demonstrated better performance that the other hospitals. From seven aspects, the first, third, fifth, sixth and seventh aspects showed that according to the patients, Harapan Bunda hospital had the best doctors' performance, while the second and the fourth aspects showed that the doctors from Fatmawati hospital had performed better.

The third part of the questionnaire, obtained different results from the second part of questionnaire. The item statements of attitude and behavior of the doctors showed that patients' perception to the doctors' interpersonal skills was still low. It described different results from the second part of the questionnaire. According to communication and interpersonal skills aspects, that we made further details in every aspect description, it showed in all aspects more that $50 \%$ of patients' opinion were appropriate, however in the third part of the questionnaire, the patients described only $20.7 \%$ of doctors that had showed good interpersonal skills. There should be further study to know what factors that influence the different opinion between the second and the third part of questionnaire. At this moment, we can state that the difference was because the interpersonal skills 
aside from the verbal communication skills of the doctors, such as gesture, feeling of empathy, listening ability, or other professional attitude, were still low. It was also occurred for Fatmawati hospital, which showed the lowest percentage (4.7\%) compared to the other hospitals (28.7\%), while in the second part, two aspects (the second and the fourth aspects) have shown that doctors in Fatmawati hospital had the best opinion from their patients than doctors in the other two hospitals, however in the third part the patients' opinion was the worst compared to the other two hospitals. It might be happened because the government as well as Fatmawati hospital was also used as a referral hospital that led to the large number of patients who have to be treated in this hospital. This might be a factor that reduced the quality of services and doctors' professionalism. It can limit the length of time for doctors to interact with their patients.

\section{Conclusion}

This study concluded that there is significant difference on doctors'communication and interpersonal skills in different Jakarta's hospitals, those were Syarif Hidayatullah, Harapan Bunda and Fatmawati hospital. From our data of the aspects of communication and interpersonal skills of Kalamazoo Consensus, was seen that the doctors' communication and interpersonal skills were better in building relationship with patients, while the lowest aspect was in the opening interview and having discussion with patient and giving additional information and closing discussion with patients. In all aspects of interpersonal skills, doctors in Syarif Hidayatullah hospital had the lowest skill compared with the other hospitals (Fatmawati and Harapan Bunda hospital). Doctors in Fatmawati hospital had the highest percentage in understanding patients' perspective and opening interview and having discussion with patients. While the rest of the aspects of communication and interpersonal skills were best for doctors in Harapan Bunda hospital.

In contrast, from the data about attitudes and interpersonal behavior, the interpersonal skills of doctors according to patients were still (20.7\%), with the lowest percentage in Fatmawati hospital (4.7\%). There should be further research to study what factors that influence the doctors performance in different hospitals and what factors that influence the different opinion in skills and behaviour from patients' perception. The weaknesses of this study were that it was not specifically range the age of the respondents and the encounters of the patients. It was also did not asked on how long that the interaction with the doctor was taken time. However, as the preliminary survey to the patients, this research may provide a description to doctors, medical education and the hospitals about recent condition of the doctors' services and what feedback should be considered to improve service quality and performance evaluation of the doctors' services, so that, the appropiate intervention can be made.

Acknowledgements: We would like to thank the enumerators who helped to collect the data. We are also grateful to the grant of Research Unit of the State Islamic University of Syarif Hidayatullah Jakarta, which has supported for funding this study.

\section{References}

Birkett, M. (2014). Self-compassion and empathy across cultures: Comparison of young adults in China and the United States. International Journal of Research Studies in Psychology, 3(3), 25-34. http://dx.doi.org/10.5861/ijrsp.2013.551

Claramitha, M. (2012). Doctor-patient communication in a culturally hierarchical context of Southeast Asia: A partnership approach. Doctoral dissertation in Medical Education. University of Maastricht, Maastricht, Netherland.

Dharmawan, T. (2010). Indonesian doctors' attitude. Jakarta Post. Retreived December 22, 2013, from http://www.thejakartapost.com/news

Duffy, F. D., Gordon, G. H., Whelan, G., Cole-Kelly, K., Frankel, R., et al (2004). Assessing Competence in Communication and Interpersonal Skills: The Kalamazoo II Report. Academic Medicine, 79(6), 
Patients' perception on interpersonal skills of doctor-patient relationship in three Indonesian hospitals

495-507. http://dx.doi.org/10.1097/00001888-200406000-00002

Gibson, J.L., Ivancevich, J.M., Donelly, J. H., \& Konopaske, R. (2006). Organizations (12 ${ }^{\text {th }}$ ed). New York:

McGraw-Hill Companies, Inc.

Hayes, J. (1991). Interpersonal skills: Goal-directed behavior at work. New York: Routledge. http://dx.doi.org/10.4324/9780203297452

Herqutanto, Basuki, E., Jauzi, S., \& Mansyur, M. (2011). Knowledge and skills of the doctors and the influencing factors about doctor-patient communication [In Indonesia]. Journal of Indonesia Medical Association, 61, 195-199.

Indonesian Medical Council. (2012). Regulation of Indonesian Medical Council no 11 about Standard of Competences of Indonesian Medical Doctor [In Indonesia]. Jakarta.

Iragiliati, E. (2006). Politeness, Forms of Address and Communicative Codes in Indonesian Medical Discourse. Jurnal Bahasa dan Seni, 34, 19-35.

Khattak, A., Alvi, M.I., Yousaf, M.A., Abideen Shah, S. Z., Turial, D., \& Akhter, S. (2012). Patient Satisfaction A comparison between public and private hospitals of Peshawar. International Journal of Collaborative Research on Internal Medicine \& Public Health, 4(5), 713-722.

Kurtz, S., Silverman, J., \& Draper, J. (2005). Teaching and Learning Communication Skills in Medicine (2 ${ }^{\text {nd }}$ ed.). United Kingdom: Radcliffe Publishing Ltd.

Lee, K. H., Seow, A., Luo, N., \& Koh, D. (2008). Attitudes towards the doctor-patient relationship: a prospective study in an Asian medical school. Medical Education, 42(11), 1092-1099. http://dx.doi.org/10.1111/j.1365-2923.2008.03157.x

Makaul, G., Zick, A., \& Green, M. (2007). An evidence-based perspective on greetings in medical encounters. Arch Intern Med, 167(11), 1172-1176. http://dx.doi.org/10.1001/archinte.167.11.1172

Nelson, R., \& Vega, C. (2008). Improving Communication Skills Enhances Efficiency and Patient-Clinician Relationships. Medscape Cardiology Education.

Pramono, M. A. (2005). The association of patient perception on the quality services of doctors and nurses to the willingness of re-encounter after hospitalized in Kartini Public Hospital, year 2005 [In Indonesia]. Masteral thesis. Diponegoro University, Semarang, Indonesia.

Project of the ABIM Foundation AAF, and European Federation of Internal Medicine. (2002). Medical professionalism in the new millennium: A doctor charter. Annals Internal Medicine, 136(3), 243-246. http://dx.doi.org/10.7326/0003-4819-136-3-200202050-00012

Sadikin, Z. D. (2008). Professionalism for Profession as Medical Doctor [In Indonesia]. Majalah Kedokteran Indonesia, 95-99.

Stern, D. T. (2006). Measuring medical professionalism. New York: Oxford University Press.

Suryawati, C., Dharminto, \& Shaluhiyah, A. (2006, December). Development of indicator for hospitalized patient satisfaction in Central Java Province [In Indonesia]. Jurnal Manajemen Pelayanan Kesehatan, 9, 177-184.

Wagner, P., Hendrich, J., Moseley, G., \& Hudson, V. (2007). Defining medical professionalism: a qualitative study. Medical Education, 41, 288-294. http://dx.doi.org/10.1111/j.1365-2929.2006.02695.x 
Ekayanti, F., Dwiyanti, S., \& Nasrudin, N. 